\title{
REVISTA
}

IIESCIÊECIA

\section{PRÁTICAS AVALIATIVAS E CONCEPÇÕES PEDAGÓGICAS UTILIZADAS PELOS PROFESSORES DO CURSO TÉCNICO EM MECÂNICA DO INSTITUTO FEDERAL DO ESPÍRITO SANTO - IFES}

\author{
EVALUATION PRACTICES AND PEDAGOGICAL CONCEPTIONS USED BY \\ TEACHERS OF THE MECHANICAL TECHNICAL COURSE OF THE HOLY \\ SPIRIT FEDERAL INSTITUTE - IFES
}

\begin{abstract}
Sebastiao de Oliveira Instituto Federal de Educação, Ciência e Tecnologia do Espírito Santo. E-mail: oliveira@ifes.edu.br.
\end{abstract}

Artigo submetido em 02/06/2020, aceito em 10/07/2020 e publicado em 28/08/2020.

\begin{abstract}
Resumo: A escola não pode estar desvinculada da vida, do mundo que a rodeia, precisa estar em sintonia com a comunidade e com o tempo em que se vive. Nesse sentido, a avaliação é uma tarefa didática necessária e permanente do trabalho docente e deve acompanhar passo a passo o processo de ensino-aprendizagem. Assim, este trabalho objetiva identificar instrumentos e técnicas utilizadas pelos professores do Curso Técnico em Mecânica do Instituto Federal do Espírito Santo(Ifes) no que diz respeito à avaliação de seus alunos e concepções pedagógicas. Além disso, pretendeu-se verificar se os professores são informados sobre os fundamentos teóricos que orientam a proposta de avaliação da aprendizagem do curso. A metodologia utilizada consistiu em um estudo de caso de caráter quantitativo e qualitativo, exploratório e descritivo. Utilizou-se como instrumento um questionário estruturado com perguntas fechadas e semiabertas, devidamente validado, contando com a amostra de 57 professores. A análise dos dados foi descritiva, por meio de tabelas de frequência absoluta e relativa. Os resultados revelaram que o grupo de professores, frequentemente, aplica uma diversidade de técnicas/instrumentos, entre os quais destacam-se: trabalhos acadêmicos (82,5\%); prova mista (77,2\%); prova dissertativa (61,4\%); prova objetiva (54,4\%); e seminários (50,9\%). No que diz respeito às concepções pedagógicas utilizadas, 52,6\% opta pela tecnicista, 40,4\% pela humanista moderna e $31,6 \%$ pela humanista tradicional. Já no que se refere ao conhecimento dos professores sobre o sistema de avaliação praticado no curso, $50,9 \%$ dos participantes informaram que o conhecem totalmente e $49,1 \%$ parcialmente. Por fim, diante da análise dos resultados, foi possível concluir que as práticas avaliativas e concepções pedagógicas suas implicações para o desenvolvimento da autonomia e criatividade dos alunos necessitam se mais trabalhadas, considerando maior discussão com os professores sobre essa temática, por parte do grupo pedagógico.
\end{abstract}

PALAVRAS-CHAVE: educação; curso técnico em mecânica; práticas avaliativas; concepções pedagógicas.

Abstract: School cannot be detached from life, from the world that surrounds it; need to be in tune
with the community and the time you live. In this sense, evaluation is a necessary and permanent
didactic task, and it must follow the process of teaching and learning step by step. Thus, this paper
aimed at identifying instruments and techniques used by the Mechanical Technical Course teachers of
the Federal Institute of Espírito Santo - Ifes in order to evaluate their students as well as verifying the
pedagogical concepts that support their teaching practice. We also intended to ascertain if the teachers
are informed about the theoretical foundations that guide the learning assessment proposal of the 
course. The methodology consisted on a quantitative and qualitative case study, also exploratory and descriptive. The instrument adopted was a duly validated structured questionnaire with closed and semi-open questions, with a sample of 57 (fifty-seven) teachers. Data analysis was descriptive, through the use of absolute and relative frequency tables. The results revealed that the group of teachers often applies a diversity of techniques/instruments, among which we can highlight: academic papers $(82,5 \%)$; mixed tests $(77,2 \%)$; essay tests $(61,4 \%)$; objective tests $(54,4 \%)$; and seminars $(50,9 \%)$. Concerning the pedagogical conceptions adopted by the teachers, 52,6\% opts for the technicist, whereas $40,4 \%$ for the modern humanist and $31,6 \%$ for the traditional humanist. When considering the teaches' knowledge on the evaluation system applied on the referred course, $50,9 \%$ of the participants informed that they have a fully understanding of it, whereas $49,1 \%$ partial knowledge. To sum up, after analyzing the results, it was possible to conclude that the evaluation practices as well as the pedagogical conceptions and their implications for the development of autonomy and creativity of students need to be more worked, taking into consideration in further discussion with teachers about this subject on the part of the educational group.

Keywords: education; technical course in mechanics; evaluative practices; pedagogical conceptions.

\section{INTRODUÇÃO}

$\mathrm{Na}$ sociedade, reserva-se às escolas o poder de conferir notas e certificados, de atestar o conhecimento ou a capacidade do indivíduo, tornando, assim, imensa a responsabilidade de quem avalia. Barbosa (2008) " [...] informa que a avaliação é comumente acompanhada de dúvidas, incertezas e, muitas vezes, de incoerências [...]". A avaliação é uma reflexão sobre o nível de qualidade do trabalho escolar, tanto do professor como dos alunos. Mas, para a grande maioria das pessoas que passou por uma escola, há sempre a lembrança de vários instrumentos/técnicas utilizados pelos professores para avaliar, tais como prova dissertativa, objetiva, mista (dissertativa e objetiva), seminários, trabalhos acadêmicos, discussões em grupo, participação nas atividades escolares, estudo dirigido. Isso se deve, sem dúvida, para alguns indivíduos a experiências negativas com relação à avaliação.

A necessidade de se apresentar uma alternativa para a avaliação partiu do momento em que se verificou, junto ao grupo de professores do Curso Técnico em Mecânica do Instituto Federal do Espírito Santo (Ifes), que as provas que vinham sendo aplicadas aos alunos para atribuir um valor numérico não estavam atendendo às expectativas didáticas e pedagógicas da Educação, uma vez que:

No âmbito da didática e da
organização escolar, é necessário
refletir sobre como os professores
concebem as práticas avaliativas e
como estas podem contribuir na
construção de uma aprendizagem
significativa dos alunos. Isto porque,
a educação entendida a partir da
transmissão e memorização de
informações, mesmo ultrapassada nas
discussões e propostas educacionais,
ainda se encontra presente no modo
de ensinar e também na forma de
avaliar como quantificadora, seletiva
e competitiva, a qual pouco auxilia
alunos e professores no processo
educativo (RECHE; MORAES, 2011,
p. 12.639).

Nesse sentido, as provas até pouco tempo usadas, na prática, eram instrumentos de mensuração que somente forneciam um valor numérico para serem registrados na ficha de "Aproveitamento e Assiduidade" do aluno. Isso ocorria para mais tarde ser somada a outros valores encontrados, sem indicar um número que, conforme o critério do Curso Técnico em Mecânica do Ifes, poderia então avançar ou não o aluno de uma série para outra. Através da avaliação diagnóstica com os professores entrevistados viu-se que para que a avaliação não seja apenas para medir quantidade de notas baixas, e sim para o 
professor possa também avaliar o seu trabalho.

As concepções que regem as ações de todas as pessoas envolvidas no processo de avaliação sejam elas alunos, família ou profissionais da educação são direta e indiretamente influenciados pela sociedade capitalista na qual se vive. $\mathrm{Na}$ avaliação educacional enquanto campo de estudo e pesquisa torna-se necessária à formação do professor para que engajado num processo pedagógico crítico e reflexivo possa assegurar o encaminhamento de ações docentes favoráveis ao processo ensino aprendizagem.

Se o aluno não conseguiu concluir os conhecimento e as competências que a instituição pretendia que ele o fizesse, é classificado como fracassado, chegando a alguns casos ser excluído socialmente do processo acadêmico. A forma pela qual o saber e o não saber são vividos no cotidiano escolar torna-se relevante para a compreensão dos mecanismos que possibilitam a construção do sucesso de alguns e o fracasso de muitos. A escola determina quais competências que o aluno deve adquirir.

De acordo com Piletti (1987, p. 190)

Avaliação é um processo contínuo de pesquisa que visa interpretar os conhecimentos, habilidades e atitudes dos alunos, tendo em vista mudanças esperadas no comportamento, propostas nos objetivos educacionais, a fim de que haja condições de decidir sobre alternativas do planejamento do trabalho do professor e da escola como um todo.

Para Souza (1993, p. 97), a avaliação "o ritual é improdutivo quando se considera o papel da avaliação com meio de promover o aprimoramento pedagógico, é produtivo e eficiente como meio de controlar e adaptar as condutas sociais dos alunos". Silva; Calado (1986) apresenta uma proposta democrática de avaliação onde "todos avaliam todos", ou seja, a participação real de todos os envolvidos no processo. A proposta está baseada no tripé: aluno-professo- CTA (Corpo Técnico Administrativo). Essa proposta desloca o peso da decisão centralizada no professor e corrige o desvios autoritários, permitindo que o Conselho de Classe apresente sugestões de melhoria para o processo ensinoaprendizagem do aluno, e que tenha ganho reais no seu conhecimento, valorizando os aspectos cognitivos, sócio-afetivos e psicomotores.

Conforme aponta Carvalho (1987, p. 357),
A tarefa de avaliar não é fácil. Planejar uma boa prova; redigir com clareza e precisão uma questão objetiva; corrigir criteriosamente uma dissertação; interpretar de forma adequada o valor de um teste é atividade complexa e que exige bom preparo do professor.

Apesar de se chamar essa prática de avaliação da aprendizagem, nada havia de real. Não se avaliava, apenas registravam os números de pontos que os alunos tinham alcançados no teste. Os professores não estavam preocupados com $\mathrm{o}$ processo ensino-aprendizagem, apenas as respostas dos testes estavam em julgamento, conforme diagnóstico desenvolvido para esta pesquisa. $\mathrm{O}$ processo de desenvolvimento do aluno não era levado em consideração. O aluno era preparado para responder os testes, que, de acordo com Luckesi (2002), “[...] é desta forma que os docentes na maioria das vezes interpretam o processo de avaliativo para os alunos, a classificação".

Usa-se a denominação avaliação, mas vale-se de provas e testes, por serem mais compatíveis com o contexto da sociedade e mais fáceis de serem executadas. Com essa prática corre-se o risco de não ser confiável, considerando possíveis falhas a que esses procedimentos estão sujeitos. Como sugere Luckesi (1995), “[...] provas e exames servem 
apenas para verificar o grau ou nível de desempenho em apenas um aspecto do desenvolvimento do aluno".

A grande falha da prática da avaliação, além do contexto referido, está em valer-se prioritariamente da função classificatória em detrimento das demais funções. Luckesi (1995, p. 34) assim confirma essa posição:

A atual prática da avaliação escolar estipulou como função do ato de avaliar a classificação e não o diagnóstico como deveria ser constitutivamente. Ou seja, o julgamento do valor que teria função de, possibilitar uma nova tomada de decisão sobre o objeto avaliado, passa a ter a função estática de classificar um objeto ou um ser humano histórico num padrão definitivamente determinado.

A função da avaliação fica descaracterizada quando a ênfase é dada apenas ao aspecto classificatório. Segundo Ferreira (1992, p. 4), deixa de "[...] ser encarada como um meio de fornecer as informações sobre o processo, tanto para que o professor conheça os resultados de sua ação pedagógica, como para o aluno verificar seu desempenho[...]". O cotidiano escolar está todo permeado por esta prática avaliativa que se distanciou da função diagnóstica ou formativa. Essa função é negligenciada e desconsiderado o seu verdadeiro significado.

Dessa forma, o que se pode perceber é que, ainda nos dias de hoje, “[...] o exercício pedagógico escolar é atravessado mais por uma pedagogia do exame que por uma do ensinoaprendizagem [...]" (RECHE; MORAES, 2011, p. 12.639).

Mesmo consciente das atuais concepções da educação (dialética, neoliberal, pós-moderna), o professor ainda pratica uma avaliação nos moldes da concepção tradicional. $\mathrm{O}$ professor, principal responsável para operacionalizar essa mudança, ainda que tenha base consistente em uma teoria de aprendizagem que lhe norteie os rumos para a modernidade para mudar a avaliação, precisa rever os outros aspectos que envolvem o processo ensinoaprendizagem (FERREIRA, 2002). A maioria dos professores encontram barreiras em desenvolver habilidades por intermédio da avaliação diagnóstica ou formativa, seja por questionamento dos pais e alunos, pela subjetividade e o aspecto não quantificável da função, seja pela dificuldade de medir o que é de natureza qualitativa, como atitudes, hábitos, destreza, valores.

Muitos desconhecem o que é proclamado sobre novas concepções de avaliação, e os que estão conscientes vivem uma contradição na sua prática, comprovada por meio do que é registrado nos planos de curso e o que é operacionalizado, não só nos momentos de avaliação, mas também em todo o processo ensino-aprendizagem.

Há uma responsabilidade muito grande sobre o professor, quanto à contextualização do processo de avaliação, que reflita os novos parâmetros da educação. Alheios à sua vontade, existem muitos fatores determinantes, quer de ordem pessoal ou institucional, que dificultam uma prática avaliativa coerente com novas concepções (FERREIRA, 2002).

A alternativa para a avaliação é uma tentativa de se trabalhar com mais realidade na verificação da aprendizagem, porque não é possível se fazer uma perfeita analise do conteúdo apreendido pelo aluno. Mas, partindo do pressuposto de que se pode melhorar essa prática, surge a ideia de planejar uma maneira de se aproximar mais da realidade educacional e de se fazer dela um processo e não um momento isolado do contexto educacional. A Avaliação deve ser assumida como um meio de averiguar como os objetivos propostos para o processo de ensinoaprendizagem estão sendo construídos e 
como um elemento orientador para os alunos e professores (HAYDT, 1987).

Assim, para contribuir com a
apropriação de saberes de maneira
significativa, a função da avaliação
vai além de constatar, verificar ou
medir, ela deve se pôr a serviço das
aprendizagens o máximo possível',
principalmente porque precisa estar
compromissada em auxiliar o aluno a
aprender e o professor a ensinar
(RECHE; MORAES 2011, p.
12.639).

Nesse sentido, avaliar bem os alunos tem sido "sempre" um dos maiores desafios para o trabalho educacional, uma vez que pode representar para eles a abertura ou o fechamento de possibilidades de estudar, aprender e se construir como cidadãos em processo de formação. A avaliação da aprendizagem supõe sempre a existência de um referencial teórico, no qual estão implícitos os conceitos da pessoa humana, da sociedade, da educação e avaliação, mesmo que não se tenha consciência deles.

Para este trabalho, foram realizadas entrevistas com professores do Curso Técnico em Mecânica do Ifes que motivou analisar as formas de considerar e entender se o comprometimento deles estava influenciando o aprendizado dos alunos, pois atribuía-se um valor numérico, não se observava os aspectos comportamentais, cognitivo e afetivo no momento da avaliação para permitir uma aprendizagem significativa. A partir das entrevistas surgiram ideias para encontrar uma forma de equilíbrio entre professores e alunos se auto-avaliarem, e, caso necessário, reformulação do plano de ensino, sua metodologia e até mesmo a maneira de mensurar o conhecimento do aluno.

O trabalho ora desenvolvido surgiu justamente das entrevistas. Dessas se chegou à conclusão que havia necessidade de reformular vários elementos que compõem o processo ensino-aprendizagem do Ifes, principalmente no que se refere à avaliação.
Foram construídos os objetivos para identificar as práticas avaliativas e concepções pedagógicas utilizadas pelos professores do Curso Técnico em Mecânica do Ifes e verificar se os professores são informados sobre os fundamentos teóricos que orientam a proposta de avaliação da aprendizagem do referido curso.

\section{PROCESSOS METODOLÓGICOS: MATERIAIS E MÉTODOS}

\subsection{QUANTO ÀS CARACTERÍSTICAS}

\subsubsection{Quanto à natureza}

Trata-se de um estudo quantitativo e qualitativo, que busca analisar quais práticas avaliativas e concepções pedagógicas são utilizadas pelos professores do Curso Técnico em Mecânica do Ifes e se são informados sobre os fundamentos teóricos que orientam a proposta de avaliação da aprendizagem do curso em pauta.

A investigação quantitativa tem como objetivo trazer estatiscamente dados, indicadores e tendências observáveis (THOMAS; NELSON, 2002, p. 35).

Para Bauer e Gaskell (2004, p. 21) os,

Enfoques quantitativos e qualitativos são mais que apenas diferenças entre estratégias de pesquisa e procedimentos de coleta de dados. Esses enfoques representam, fundamentalmente, diferentes referências epistemológicas para teorizar a natureza do conhecimento, a realidade social e os procedimentos para compreender esses fenômenos.

Para os mesmos autores (2004, p. 22), a pesquisa quantitativa lida com números, usando modelos estatísticos com intuito de explicar os dados, assim, pode ser considerada como centrada ao redor do levantamento dos mesmos e de questionários, apoiada pelo software Statical Package for Social Sciences (SPSS). 
Já o estudo de natureza qualitativa envolve um registro preciso e detalhado do que acontece em determinado ambiente, ocorrendo ainda a interpretação e a análise de dados por meio de suas descrições, narrativas, citações e elaboração de gráficos e/ou e tabelas (THOMAS; NELSON, 2002, p. 35).

\subsubsection{Quanto aos objetivos}

Esta pesquisa procura explorar as concepções dos professores do ensino profissionalizante do Curso Técnico em Mecânica do Ifes, quanto ao fenômeno avaliativo.

Em relação aos objetivos, a pesquisa pode ser considerada como exploratória, considerando que tem como principal finalidade "[...] desenvolver, esclarecer e modificar conceitos e ideias, com vista na formulação de problema mais preciso ou hipóteses pesquisáveis para estudos posteriores" (GIL, 1994, p. 44). Segundo Lakatos; Marconi (2001), um estudo exploratório se caracteriza por enfatizar a descoberta de ideias e discernimentos.

Já a pesquisa descritiva, como o próprio nome sugere, vem a ser "[...] a descrição das características de uma determinada população ou fenômeno ou, então, o estabelecimento de relações entre variáveis [...]" (GIL, 1994, p. 42).

\subsubsection{Quanto aos procedimentos}

Trata-se de um estudo de caso o qual Thomas et al. (2006) afirmam que uma das principais vantagens da abordagem do estudo de caso é que ele pode ser proveitoso na formulação de novas ideias e hipóteses sobre áreas problemáticas, especialmente para áreas em que não existe uma estrutura ou um modelo bem definido.

Nesse sentido, Martins (2008) informa que o trabalho de um estudo de caso é precedido pela exposição do problema de pesquisa - questões orientadoras - do enunciado de proposições - teses - que compõem a teoria preliminar que será avaliada a partir dos achados da pesquisa.

\subsection{DELIMITAÇÃO DOS SUJEITOS}

\subsubsection{Local da pesquisa}

A pesquisa foi realizada no Instituto Federal do Espírito Santo (Ifes), localizado em Vitória - Capital do Estado do Espírito Santo - Brasil.

\subsubsection{População e Amostra da pesquisa}

A população dessa pesquisa constou de professores e alunos de ambos os sexos, que atualmente lecionam do Curso Técnico em Mecânica do Ifes. Este artigo analisa apenas os questionários respondido pelos professores. A amostra foi constituída de cinquenta e sete professores.

\subsection{VARIÁVEIS PESQUISADAS}

A variável dependente está aqui representada pelo sistema avaliativo dos alunos.

A variável independente está aqui representada pelos professores do Curso Técnico de Mecânica do Instituto Federal do Espírito Santo - Ifes.

\subsection{DELIMITAÇÕES DO ESTUDO}

Devem-se apontar aqui algumas limitações metodológicas deste estudo. Por tratar-se de amostra de conveniência, foi escolhida intencionalmente uma instituição pública para efeito de contraste da realidade socioeconômica e cultural dos professores. Portanto, possíveis generalizações dos dados podem ser feitas apenas com muita cautela. 
De forma relativamente surpreendente, não se obtive recusas de professores em responder aos questionários. Isto talvez se deva a um extremo cuidado no esclarecimento sobre os objetivos da pesquisa e na garantia enfática do anonimato. Nos dias de aplicação, a classe estava, de modo geral, cheia, indicando que não houve faltosos para a realização da pesquisa.

\subsection{SELEÇÃO DOS INSTRUMENTOS}

Utilizou-se de um instrumento de pesquisa com perguntas fechadas e semiabertas, representado por um questionário para verificar e constatar se os professores são informados sobre os fundamentos teóricos que orientam a proposta de avaliação do curso técnico de mecânica do Ifes.

Em relação à utilização de questionários, Gil (1994, p. 124), afirma que "[...] esse instrumento constitui hoje uma das mais importantes técnicas disponíveis para obtenção de dados nas pesquisas sociais [...]". Reforçando o uso dessa técnica, Thomas e Nelson (2002, p. 34) "[...] explicam que a justificativa principal para se utilizar um questionário é a necessidade de se obter respostas de pessoas de uma vasta área geográfica". O que confirma a fala de Richardson et al. (1999) de que os questionários permitem a obtenção de informações de um número variado de pessoas e são de fácil tabulação dos dados em pouco tempo. Os questionários foram distribuídos em várias questões para os professores, sendo fechadas e semiabertas para facilitar $o$ tratamento estatístico dos dados.

\subsection{VALIDAÇÃO DOS QUESTIONÁRIOS}

Para validação dos questionários foram consultados professores doutores, que opinaram sobre a montagem, sugeriram modificações, inclusão de dados necessários para a montagem, além de alguns questionamentos sobre o tema da pesquisa.

A elaboração e a utilização do questionário de pesquisa devem atender a critérios que possibilitem a segurança e a confiabilidade do instrumento constituído. Esses critérios chamados de características psicométricas são representados por três importantes medidas: validade, reprodutibilidade e objetividade (RABACOW et al., 2006).

Mais especificamente, a validade representa o quanto o teste mede aquilo que se dispôs ou foi designado a medir. A reprodutibilidade é um indicador de mensuração da consistência ou repetição de uma observação e a objetividade indica a maneira como o instrumento foi administrado o que define as possibilidades de sua apuração, permitindo uma visão de como a inferência afetou os sujeitos da pesquisa.

\subsection{PROCEDIMENTOS PARA COLETA DOS DADOS}

$\mathrm{Na}$ primeira fase da pesquisa foram entrevistados seis professores, por meio do questionário, formalizando, dessa forma, a entrevista diagnóstica para tomar conhecimento das estratégias de avaliação e concepções da educação que eram desenvolvidas pelos docentes da instituição.

Utilizou-se, também, como técnica de coleta de dados da pesquisa um questionário com dezoito perguntas fechadas e semiabertas aplicados aos professores, para identificar o universo da avaliação e as concepções da educação que eram desenvolvidas no Ifes, no curso técnico em mecânica.

\subsection{QUESTÕES ÉTICAS DA PESQUISA}

Os sujeitos da pesquisa receberam em anexo aos instrumentos um termo de 
Consentimento Livre e Esclarecido e ainda uma Carta de Apresentação, de acordo com o preconizado na Resolução 196/96 do Conselho Nacional de Saúde. No referido termo, constava a garantia ao sigilo total do indivíduo e a de poder abandonar a pesquisa se assim desejasse, bem como uma explanação sobre os objetivos e justificativas da pesquisa a qual estava participando.

\subsection{TRATAMENTO ESTATÍSTICO}

Para análise dos dados coletados foi realizada a análise descritiva, por meio de tabelas de frequência absoluta e relativa. Foi utilizado o pacote estatístico IBM SPSS 20.0 para as análises.

\section{RESULTADOS E DISCUSSÃO}

Os dados e informações a seguir originaram-se da análise dos resultados obtidos pelo estudo desenvolvido com os professores do Curso Técnico em Mecânica do Ifes.

Tabela 1: Instrumentos/técnicas utilizados pelos professores para avaliar seus alunos

\begin{tabular}{lcc}
\hline Resposta & Número & Percentual \\
\hline $\begin{array}{l}\text { Prova dissertativa } \\
\text { Prova objetiva }\end{array}$ & 35 & 61,4 \\
$\begin{array}{l}\text { Prova mista } \\
\text { (dissertativa e }\end{array}$ & 44 & 54,4 \\
objetiva) & & 77,2 \\
Seminários & 29 & 50,9 \\
Trabalhos acadêmicos & 47 & 82,5 \\
$\begin{array}{l}\text { Discussões em grupo } \\
\text { Participação nas }\end{array}$ & 14 & 24,6 \\
atividades escolares & 24 & 42,1 \\
$\begin{array}{l}\text { Estudo dirigido } \\
\text { Debate sobre temas }\end{array}$ & 11 & 19,3 \\
atuais & 5 & 8,8 \\
\hline
\end{tabular}

Fonte: Arquivo pessoal (2017)

A Tabela 1 demonstra a diversidade de instrumentos/técnicas utilizados pelos professores, mas as concentrações estão nos trabalhos acadêmicos $(82,5 \%)$, prova mista $(77,2 \%)$, prova dissertativa $(61,4 \%)$, prova objetiva $(54,4 \%)$ e seminários $(50,9 \%)$. Ferreira $(1992$, p. 5) orienta que "[...] o professor deve estar atento para não empobrecer o seu processo de avaliação, aplicando só um tipo de instrumento".

Para Saul (1988, p. 48) “[...] a avaliação da aprendizagem definida como uma das dimensões do papel do professor transformou-se numa verdadeira 'arma', em um instrumento de controle que tudo pode[...]".

O mesmo autor ainda comenta que o professor se utiliza dessa poderosa "arma" como suposto elemento motivador para conseguir a ordem e um clima favorável para a aprendizagem. Já Lima $(1996$, p. 45) comenta que “[...] provavelmente a maior parte dos professores não conseguiria dar aula se não dispusesse do poder de reprovar". Ainda sobre este aspecto, Oliveira (1991, p. 41) afirma que "[...] a manutenção do clima de tensão, o medo parecem ser as grandes armas da escola e do professor".

Por conta do contexto vivenciado no cotidiano escolar, muitos professores valem-se das diversos instrumentos/técnicas de avaliação como uma "arma", instrumento de punição, demonstração de poder e autoridade, desconsiderando, muitas vezes, os vários benefícios que esses instrumentos/técnicas de avaliação podem oferecer para o processo ensino-aprendizagem.

Tabela 2: Concepção fillosófica de educação que ilumina/orienta a prática avaliativa dos professores

\begin{tabular}{lcc}
\hline Resposta & Número & Percentual \\
\hline Humanista tradicional & 18 & 31,6 \\
Humanista moderna & 23 & 40,4 \\
Tecnicista & 30 & 52,6 \\
Dialética & 9 & 15,8 \\
Neoliberal & 3 & 5,3 \\
Pós-moderna & 2 & 3,5 \\
Não responderam & 16 & 28,1 \\
\hline
\end{tabular}

Fonte: Arquivo pessoal (2017) 
A Tabela 2 apresenta caraterística para as concepções filosóficas de educação que ilumina/orienta a prática avaliativa dos docentes do Curso Técnico em Mecânica do Ifes, com percentual para concepção humanista tradicional $(31,6 \%)$, humanista moderna $(40,4 \%)$ e tecnicista $(52,6 \%)$. Nas demais concepções, apenas $24,6 \%$ se concentram em dialética, neoliberal e pósmoderna, tendo inclusive alguns que não responderam $(28,1 \%)$. Essa situação se caracteriza pelo modo como a escola destaca o processo burocrático, que evidencia em seu cotidiano.

O que se observa nessa tabela é que a maioria dos professores $(52,6 \%)$ utiliza a concepção tecnicista para as suas avaliações. Isso se caracteriza pela estrutura curricular do Curso Técnico em Mecânica do Ifes e pela formação tecnológica da maioria dos professionais.

Essa situação se apresenta, segundo Cunha (1995, p. 36), como sendo "[...] o fato de o professor ter tido uma educação autoritária e punitiva pode fazê-lo tentar repelir esta forma no seu cotidiano docente, mas pode também levá-lo a repetir esta prática".

Já a concepção humanista moderna apresenta 40,4\% dos professores pesquisados. Observa-se que alguns autores discutem essa concepção com base nas abordagens cognitivista e humanista, sendo que o professor é aquele que expressa e assume o papel de orientador. Ele conduz e orienta o processo, cria condições para que o aluno analise seu contexto e produza cultura, conduz o processo de forma participativa, por meio do diálogo e da cooperação. Trata o aluno como pessoa concreta, determinada pelo seu contexto histórico e que o torna um ser individual (MIZUKAMI, 1986).

É nesse contexto que se concretiza uma prática de avaliação determinada pelo postulado teórico do professor e pela concepção que ele tem dessa prática. Essa posição está referendada por Lüdke e Mediano (1994, p. 30) na seguinte expressão "[...] certamente o que o professor faz em avaliação é condicionado pela concepção que tem desse processo mais amplo de ensino e aprendizagem". É determinada também pela sua história, pela sua cultura e conjuntura social onde se desenvolveu. Toda atividade do professor é um reflexo daquilo que ele vivenciou.

Com essa afirmação, muitos professores tratam a avaliação da maneira como vivenciaram na sua experiência escolar. O que o professor pratica hoje é, segundo Hoffmann (1997, p. 28), um “[...] reflexo do modelo de avaliação vivenciado enquanto educandos e dos pressupostos teóricos que embasaram seu curso de formação".

Pode-se dizer, de acordo com os resultados da tabela acima, que grande parte dos professores se concentrou nas concepções tradicionais, humanista moderna e tecnicista o que respalda na sua vivência, enquanto aluno do curso técnico ou até mesmo da sua formação universitária, mantendo, dessa forma, as mesmas características adquiridas ao longo dos anos.

Após essas considerações sobre o professor, peça fundamental na operacionalização do processo de avaliação, cuja postura é produto de sua concepção, de seu contexto históricosocial, de sua prática na convivência de seu cotidiano escolar, coadjuvado pelas condições que a instituição proporciona para a consecução de sua ação pedagógica, é importante que se atente para a posição do aluno frente à avaliação.

O aluno vivencia esta experiência que irá refletir em seu futuro como profissional e ser atuante na sociedade, portanto sua compreensão do homem como máquina, fruto da visão moderna do mundo, passa a ser questionada pelas novas descobertas da ciência e gera resultados na medicina, na educação, no desenvolvimento da tecnologia, nas organizações empresariais, nas soluções urbanas. E o professor é responsável por 
agregar valor e conhecimento a este aluno ao longo de sua graduação através de processos avaliativos coerentes e com visão holística para este aluno.

Hoje, o momento histórico do qual emerge sua nova visão de mundo é necessário que o homem construa seus novos valores e conceitos para os novos tempos. É hora de reflexão, de conhecer paradigmas diferentes e perceber seus múltiplos reflexos nas formas de organização da sociedade humana moderna, que enfrenta desafios, como os problemas globais e inter-relacionais criados pelo paradigma positivista. È responsabilidade do professor ajudar ao aluno a enxergar e melhor absorver essas mudança e oferecer meios ao aluno de melhor avaliar e entender o que pode ser levar de valor agregado como conhecimento técnico cientifico na construção deste como futuro cidadão contribuinte na sociedade moderna. Estes valores devem ser apresentados nas formas corretas e justas de avaliação, levando e norteando para o lado do desenvolvimento tecnológico, e ao mesmo tempo o tornando um ser humano ativo na sociedade. A nova cultura que emerge do tempo e do espaço, e as transformações relacionadas com formas de conhecimento e experiência no mundo pós-moderno (GIROUX, 1996).

Tabela 3: Foi informado sobre os fundamentos teóricos que orientam a proposta de avaliação da aprendizagem do Curso Técnico em Mecânica do Ifes

\begin{tabular}{ccc}
\hline Resposta & Número & Percentual \\
\hline Totalmente & 29 & 50,9 \\
Parcialmente & 28 & 49,1 \\
\hline Total & 57 & 100,0 \\
\hline
\end{tabular}

Fonte: Arquivo pessoal (2017)

Segundo a Tabela 3, 50,9\% foram informados totalmente sobre os fundamentos teóricos que orientam a proposta de avaliação da aprendizagem do
Curso Técnico em Mecânica do Ifes, enquanto que $49,1 \%$ parcialmente.

O fato de $49,1 \%$ dos professores terem apresentado informação parcial dos fundamentos teóricos do curso indica que alguns deles precisariam participar mais das ações do curso que trata sobre as questões pertinentes à discussão do processo avaliativo, que consta nos artigos 66 a 83, da Regulamentação da Organização Didática dos Cursos Técnicos do Ifes (ROD, 2011, p. 21-26), tratando de temas como: mecanismo de avaliação, verificação do rendimento e da promoção, regime de dependência.

Nesse sentido, os professores que não participaram da reunião sobre os fundamentos teóricos que orientam a proposta de avaliação da aprendizagem do Curso Técnico em Mecânica do Ifes deveriam ponderar acerca do pensamento de Vasconcellos (1997), que informa que avaliar não é reprovar, mas, sim, compreender e promover, a cada momento, o desenvolvimento pleno de quem vivência um processo de aprendizagem, e que o processo de mudança da prática educacional envolve três aspectos a serem observados pelos professores: a dificuldade de alterar a prática, o papel da reflexão e a perspectiva de construção de uma práxis transformadora, e a questão da participação do professor como sujeito do processo de ensino-aprendizagem bem como sua formação para a sociedade.

O professor precisa considerar, inicialmente, que a reflexão encontra-se no campo da subjetividade, sendo que os obstáculos para a mudança estão tanto no aspecto subjetivo como no objetivo. A reflexão não é um processo mecânico, automático e casuístico. Ela é, portanto, uma mediação no processo de transformação, ou seja, pode agir através do sujeito, tendo por função propiciar o despertar desse sujeito, além de um conhecimento da realidade, uma nova intencionalidade e um novo plano de ação (BARBOSA, 2008). 
A avaliação hoje é um recurso para fornecer informações e não um fim em si mesma. As informações colhidas no processo são julgadas considerando as circunstâncias do objeto avaliado e critérios de valoração. A conjuntura na qual ela ocorre assume maior importância do que as notas ou classificações escolares, pois a avaliação da aprendizagem não é a tirana da prática educativa. Ela é amorosa, inclusiva, dinâmica, construtiva (LUCKESI, 2002).

\section{CONCLUSÔES}

Após a análise da pesquisa e observando a Tabela 1 quanto à diversificação de instrumentos/técnicas avaliativas dos alunos no Curso Técnico em Mecânica do Ifes, percebeu-se que há diversidade de instrumentos/técnicas utilizadas pelos professores, e que as concentrações ocorrem nos trabalhos acadêmicos $(82,5 \%)$, prova mista $(77,2 \%)$, prova dissertativa $(61,4 \%)$, prova objetiva $(54,4 \%)$ e seminários $(50,9 \%)$.

Essa distribuição para formas de avaliação induz alguns professores a utilizarem diversos instrumentos/técnicas de avaliação, desconsiderando, muitas vezes, os vários benefícios que esses instrumentos/técnicas podem oferecer para o processo ensino-aprendizagem.

Isto ocorre conforme demonstra a Tabela 2, na qual a maioria dos professores encontram-se na concepção tecnicista $(52,6 \%)$. Concepção esta que apresenta padrões de aprendizagem e respostas coerentes com a metodologia diretiva e uma linha de ensino, adotada por volta de 1970, que privilegiava excessivamente a tecnologia educacional e transformava professores e alunos em meros executores e receptores de projetos elaborados de forma autoritária e sem qualquer vínculo com o contexto social a que se destinavam. Nesse sentido, há uma controvérsia com relação a essa questão, pois se as maiorias é de concepções humanista tradicional, moderna e tecnicista, como permitiriam autonomia, criatividade e personalidade aos alunos, uma vez que tais concepções são de nível controlador e autoritário.

Para a questão de verificar se os professores são informados sobre os fundamentos teóricos que orientam a proposta de avaliação da aprendizagem do Curso Técnico em Mecânica do Ifes percebeu-se que 50,9\% dos professores são informados quanto esse tópico, conforme demonstra a Tabela 3 , pois na instituição existe a Regulamentação da Organização Didática (ROD) dos Cursos Técnicos, mas ainda existe um grande percentual, $49,1 \%$, que é parcialmente informado ou não participa das discussões referentes às propostas que orientam sobre a avalição de aprendizagem do processo ensinoaprendizagem do curso.

Após a análise e diante dos resultados, foi possível concluir que as práticas avaliativas e concepções pedagógicas necessitam ser mais trabalhadas, considerando maior discussão com os professores sobre essa temática, por parte do grupo pedagógico, uma vez que ainda apresenta um percentual de $49,1 \%$ dos professores que são parcialmente informados da proposta de avaliação da aprendizagem do Curso Técnico em Mecânica do Ifes.

Além disso, atualmente, a escola precisa ser um lugar de qualidade, prazerosa e competente, que permita a transformação da sociedade. Uma escola que possibilite aos alunos uma vida cidadã plena, dentro de uma sociedade humana, democrática, justa, ética e solidária, em consonância com o nosso tempo e com a natureza do trabalho didático pedagógico.

O professor é pessoa chave dentro da sociedade moderna como contribuinte na formação pedagógica, institucional, portanto, para que a educação possa ser concebida como a vivência de experiências múltiplas e variada, tendo em vista o desenvolvimento motor, cognitivo, afetivo 
e social do aluno, ele deve contribuir efetivamente seja nas práticas avaliativas, seja criar formar de transmissão deste conhecimento técnico cientifico para $\mathrm{o}$ aluno.

Assim entendido, a avaliação da aprendizagem é um processo orientador e interativo, constituindo um desafio para o professor e também não sendo uma atividade solitária do professor: ela tem que ser compartilhada com os alunos, pais, professores e gestor escolar. Daí pode-se concluir que a avaliação é um processo contínuo, participativo, com função diagnóstica e investigativa, cujas informações devem proporcionar $\mathrm{O}$ redimensionamento da ação pedagógica e educativa, reorganizando as próximas ações de todos, no sentido de avançar no entendimento do processo de aprendizagem, evitando desta forma a concentração na avaliação formativa e somativa.

Neste sentido, é possível experimentar e viver o novo desde já, só que de forma completa, ilimitada. O que está em questão não é necessariamente fazer um trabalho docente perfeito, o que é decisivo e realmente transformador é fazer o melhor possível, pois através disso, o professor estará contribuindo para a efetiva formação da cidadania de seus alunos, permitindo a ele autonomia, criatividade e a possibilidade de resoluções de problemas na sua vida acadêmica e laboral.

\section{REFERÊNCIAS}

BARBOSA, J. R. A. A avaliação da aprendizagem como processo interativo: um desafio para o educador. Rev.

Democratizar, Rio de Janeiro, v. II, n. 1, jan./abr. 2008.

BAUER, M. W.; GASKELL, G. Pesquisa qualitativa com texto, imagem e som: um manual prático. 3. ed. Petrópolis/RJ:

Vozes, 2004.
BRASIL. Resolução 196/96. Brasília:

Conselho Nacional de Saúde (CNS).

Disponível em: <http://conselho.saude. gov.br/web_comissoes/conep/aquivos/resol ucoes/23_out_versao_final_196_encep201 2.pdf>. Acessado em: 12 ago. 2016.

BRASIL. Instituto Federal de Educação, Ciência e Tecnologia do Espírito Santo.

Regulamentação da organização didática da educação profissional técnica de nível médio; código de ética e disciplina do corpo discente do Ifes.

Vitória: Ifes, 2011.

CARVALHO, I. M. C. O processo

didático. 6. ed. Rio de Janeiro: Fundação Getúlio Vargas, 1987.

CUNHA, M. I. O bom professor e sua prática. 5. ed. Campinas: Papirus, 1995.

FERREIRA, P. R. P. Avaliar: um ato que exige mudanças. In: $19^{\circ}$ TELENFOQUE/FÓRUM. Anais... Fortaleza: IOCE, 1992.

FERREIRA, L. O contexto da prática avaliativa no cotidiano escolar. In FERREIRA, L. Retratos da avaliação: conflitos, desvirtuamentos e caminhos para a superação. Porto Alegre: Mediação, 2002.

GIL, A. C. Métodos e técnicas de pesquisa social. São Paulo: Atlas, 1994.

GIROUX, H. Jovens, diferença e educação pós-moderna. In: CASTELLS, M. et al. Novas perspectivas críticas em educação. Porto Alegre: Artes Médicas; 1996. p. 63-85.

HAYDT, R. C. C. Avaliação do processo ensino aprendizagem. São Paulo: Ática, 1987.

HOFFMANN, J. Avaliação mito e desafio: uma perspectiva construtivista. 22. ed.. Porto Alegre: Mediação, 1997. 
LAKATOS, E. M.; MARCONI, M. A. Metodologia do trabalho cientifico: procedimentos básicos. São Paulo: ATLAS, 2001.

LIMA, L. O. Conflitos no lar e na escola: educação e trabalho no capitalismo. Trad. Tomaz Tadeu da Silva. Porto Alegre: Artes Médicas, 1996.

LÜDKE, M.; MEDIANO, Z. D. (Coord.). Avaliação na escota de $1^{\circ}$ grau. 2 . ed. Campinas: Papirus, 1994.

LUCKESI, C. C. Avaliação da aprendizagem como um ato amoroso. In: LUCKESI, C. C. Avaliação da aprendizagem escolar. 12. ed. São Paulo: Cortez, 2002.

LUCKESI, C. C. Avaliação da aprendizagem escolar. 2. ed. São Paulo: Cortez, 1995.

MARTINS, G. A. Estudo de caso: uma estratégia de pesquisa. 2. ed. São Paulo: Atlas, 2008.

MIZUKAMI, M. G. N. Ensino: as abordagens do processo. São Paulo: EPU, 1986.

OLIVEIRA, D. P. T. A prática do professor em avaliação: conservadorismo ou transformação, Rev. Tecnologia

Educacional, Rio de Janeiro, v. 20, set./dez. 1991.

PILETTI, C. Didática geral. São Paulo: Atica, 1987

RABACOW, F. M.; GOMES, M. A.; MARQUES, P.; BENEDETTI; T. R. B. Questionários de medidas de atividade física em idosos. Rev. Brasileira de Cineantropometria \& Desempenho Humano, v. 8, n. 4, p. 99-106, 2006.

RECHE, B. D.; MORAES, D. A. F. As práticas avaliativas do processo de ensino e aprendizagem e as concepções dos professores. Trabalho apresentado no $X$ Congresso Nacional de Educação EDUCERE, Curitiba, 2011.p. 12.63912.648. Disponível em: http://educere. bruc.com.br/CD2011/pdf/5576_3308.pdf. Acessado em: 18 out. 2018.

RICHARDSON, R. J.; PERES, J. A. S.; WANDERLEY, J. C. V.; CORREIA, L. M.; PERES, M. H. M. Pesquisa social: métodos e técnicas. São Paulo: Atlas, 1999.

SAUL, A. M. Avaliação emancipatória: desafio à teoria e à prática de avaliação e reformulação de currículo. São Paulo: Cortez, 1988.

SILVA, Z. C.; CALADO, I. H. Avaliação escolar: uma proposta democrática. Revista Teoria Educacional. Rio de Janeiro, v.15, n.73, p. 12-20, nov./dez. 1986.

SOUZA, C. P. (Org). Avaliação do rendimento escolar. 2 ed. Campinas: Papirus, 1993.

THOMAS, J. R.; NELSON, J. K. Métodos de pesquisa em atividade física. 3 . ed. São Paulo: Artmed, 2002.

THOMAS, J. R; NELSON, J. K; SILVERMAN. Métodos de pesquisa em atividade física. 4. ed. São Paulo: Artmed, 2006.

VASCONCELLOS, C. S. Para onde vai o professor - resgate do professor como sujeito de transportação. São Paulo: Libertad, 1997. 